\title{
Intermédialités
}

Histoire et théorie des arts, des lettres et des techniques

Intermediality

History and Theory of the Arts, Literature and Technologies

\section{Archive Drift}

\section{Arthur Kroker}

Numéro 18, automne 2011

archiver

archiving

URI : https://id.erudit.org/iderudit/1009078ar

DOI : https://doi.org/10.7202/1009078ar

Aller au sommaire du numéro

\section{Éditeur(s)}

Revue intermédialités (Presses de l’Université de Montréal)

ISSN

1705-8546 (imprimé)

1920-3136 (numérique)

Découvrir la revue

Citer cet article

Kroker, A. (2011). Archive Drift. Intermédialités / Intermediality, (18), 137-149. https://doi.org/10.7202/1009078ar

\section{Résumé de l'article}

Rien de plus imaginaire que l'archive numérique. Tel un spectre brillant sort des vastes recoins de l'univers culturel, l'archive numérique s'élance dans les ciels nocturnes de l'esprit. Elle change le passé temporel en temps-réalité ; elle éclaire les horizons avec de la lumière-espace ; repliant le passé historique, elle le projette vers le futur ; elle détruit les limites fixes ; elle prend toujours les sentiers imprévisibles des attentes de l'imagination. Comme elle n'a jamais réellement d'intérêt à dire la vérité et qu'elle ne respecte pas particulièrement le concept de bunker archéologie (Paul Virilio), l'archive numérique constitue un cas très rare de phénomène culturel : c'est une matrice de codes, qui trace un arc incertain par-dessus la condition humaine, récupérant une mémoire qu'elle projette dans le présent, en confrontant d'un côté la solidité matérielle du réel à la reconstruction imaginaire du passé, en prenant de l'autre de la vitesse tandis que la matrice des codes est projetée en avant par ces champs de force gravitationnels que sont les planètes environnantes - société, économie, culture. Dans ce processus, l'archive numérique devient toujours plus intense, plus vive, plus purement imaginaire.
Ce document est protégé par la loi sur le droit d'auteur. L'utilisation des services d’Érudit (y compris la reproduction) est assujettie à sa politique d'utilisation que vous pouvez consulter en ligne.

https://apropos.erudit.org/fr/usagers/politique-dutilisation/ 


\title{
Archive Drift
}

\author{
Arthur Kroker
}

Nothing, after Wagner's concept of Gesamkunstwerk exists in a vacuum: whether our culture is now taken from YouTube or posted online with cell phones by soldiers in Iraq, we exist in a world where documents act as a kind of testimony. But once something is recorded, it's basically a file waiting to be manipulated. That's what links the concept of the remix to everything going on these days: truth itself is a remix.

Paul D. Miller (aka DJ Spooky) ${ }^{1}$

\begin{abstract}
2 rchive Drift introduces a new way of thinking about the future of the cultural archive. Rather than limit the boundaries of the archive to collections of cultural artifacts - newspapers, songs, books, journals - I would like to explore a different methodological proposition, namely that in the age of social media both the form and content of the cultural archive have been literally blown apart by the violence of digital technology. While the impact of technology on the archive is often limited to the notion that analog archives are about to be transformed into searchable databases, my hypothesis is that one of the outstanding characteristics of digital culture, particularly in the contemporary phase of social media, is that the content of the archive has suddenly and risibly expanded to encompass the totality of life itself and, moreover, that the form of the archive has been fundamentally changed by the architecture of social media. Archive drift, therefore, always has a doubled meaning; namely that the actual content of the digital archive is literally at drift-unbounded, animated, deeply relational-in the universe of social media, and that the form of the archive patterns itself on the waves of code drift within which it finds itself and, on behalf of which, the form of the digital archive increasingly comes to represent the key trajectory of technological society.
\end{abstract}

1. Paul D. Miller, The Book of Ice, New York, Mark Batty Publisher, 2011, p. 18. 


\section{SOCIAL MEDIA AND THE FUTURE OF THE ARCHIVE}

Of course, thinking about the future of archive drift is necessarily speculative since it is a matter of trying to draw into visibility larger patterns of technological destiny that have not as yet fully revealed themselves. Equally, speculating about the future implications of archival drift cannot be done within the limits of traditional research narratives for the simple reason that digital culture is always liminal, an uncertain borderland where that which is disappeared, silenced, and excluded is often more important than that which is searchable, visible, and intelligible. That is why this essay on archive drift not only takes, but demands, the right to be itself a reflexive representation of the uncanny movement of archival logic as it migrates from the perimeter of social understanding to the historical apex of the digital future. It is not yet clear why digital culture is so infatuated, even obsessed, with archivalism. One explanation for the deep affinity of archivalism and social media may be simply technological; specifically that data is itself always necessarily relational, nested, searchable and thus (digitally) archival as a matter of its own programmatic logic. While this technological explanation would explain the importance of archivalism as the software architecture of social media, it would not, however, account for the seduction of archivalism in a technological culture so feverishly dedicated to the future of the decontextualized, the dehistoricized, the dematerialized.

In this case, could it be that pursuing the question of the future of the archive in the contemporary context of social media is to tap into a deeper cultural current at work in digital reality, namely that in this age of pervasive social media there is already a strong cultural counter-current present-a dramatic precession of events by which technological society has actually begun to reverse itself, desperately animating its own archival remains-databases, network searches, the digital self conceived as a cultural artifact-as a way of energizing a technological project that always runs on empty. In this case, the radiating presence of a distinctively archival register, present seemingly everywhere in contemporary digital culture, may reflect an almost instinctive response to the disappearance of material history into digital code. Consequently, while the massive revival of archivalism in digital form may be a product of an unprecedented technological ability to archive the totality of human experience, it might also be an early sign of growing human consciousness about the disappearance of objects into symbols, events into codes, human singularities into virtual patterns. Is it possible that with the triumph of archivalism as the key trajectory of social media, we are finally present at a frenzied last feast of the human presence before it also 
disappears into the lip of the Net? In this theatre of the digital imaginary a risible sense of sacrificial violence can be detected amidst the seduction of technologically enabled archives.

So then, archive drift as the key trajectory of social media, simultaneously its final destiny and its founding ontology. Its final destiny because the evolutionary momentum of social media always seems to bend in the direction of more elaborate, immensely dense concentrations of social archives: archives of fast communication (Twitter), archives of social identity (Facebook), archives of images, sounds, and performances (YouTube), archives of photography (Flickr), meta-archives of the Internet (Google), archives of cartography (Google Maps), archives of shared genomic data (23 and me), impromtu scrappy archives of Internet memes, passing fads, niche electronic interests, and pop cultural phenomena (Tumblr), archives of social and cultural history (Wikipedia), archives of official secrets (WikiLeaks). But also as its founding ontology, because what results when the speed of social media slams into the history of the cultural artifact is that the artifact as traditionally conceived is suddenly jettisoned from the domain of the collected, the bounded, the labeled, the studied to become something radically at drift in contemporary culture.

Indeed, if digital archives can be so pervasive in contemporary culture it is, perhaps, due to the fact that in the age of social media, digital subjectivity has itself been increasingly transformed into a type of cultural artifact-one which floats in a complex web of network relations, its network identity merged with its social identity, its autobiographical narrative shaped by events in real-time as much as by the natural rhythms of life and death. For example, the long-term network visioning strategy of Google is based on the possibility that individuals will increasingly live within the data matrix of a continuous, iterative self-archiving of their own life history from the moment of birth to death. Not so much Facebook, but something like FaceLife, with the singularity of an individual life itself represented as a self-recorded data meme complete with an evolving network chronology of relationships, events, and locational data. In this futurist version of FaceLife, archival imagination is transformed into an elementary constituent of digital subjectivity. Thus conceived, nothing would ever really escape the digital archive, nor would any element of the digital archive exist that would not necessarily be distributive, relational and dynamic. Literally, the human condition would be trapped within a mnemonic machine of its own design with the inevitable consequence that the (digital) future to which the human condition is being delivered with such technological precision and force would be characterized by what might be called a sticky archive-a dense archive of relationships 
past and present that would never be allowed to slip into forgetfulness and that would, for that matter, literally cling to the digital subject like a cloud of memories, relationships and events never capable of repression or silencing.

Always more mediate than distanced, more subjective than objective, more distributive than disconnected, the future of the archive under the sign of technology is coming to be, increasingly, more about blurring the boundaries between future and past. In the digital culture thus expressed in all its intensity and complexity by social media, the archive is not only suddenly ubiquitous, but the distinguishing quality of the digital archive that surrounds us is that it is at drift in the data stream, divorced from the language of ultimate goals or definite genealogies. That the actual contents of the digital archive often range from the banal to the sublime, from tedium to fascination, only means that the material history of the digital archive is fully indeterminate. For this reason, what really matters in thinking the future of the digital archive is something more spectral and illusive, specifically the role of the digital archive that we call social media in shaping human imagination. For better or worse, life today is increasingly shaped by the power of the digital imaginary. So why not a form of thought that respects the very real presence of the digital imaginary, this archive in the wires, speaking in all its complexity to the limits and possibilities of human imagination itself? Why not, then, a form of speculative, imaginary thought that both inaugurates a duel between human imagination and the digital imaginary and that, in this clash of perspectives, begins to do that which is most prohibited-to draw into visibility those elements of the human condition which, precisely because they have been excluded and silenced by the sterile language of codes, databases, and algorithms, become the hauntologies of the digital imaginary ${ }^{2}$ In effect, why not a form of speculative, imaginative thought that works through our present situation as inhabitants of those archives, in the wires designated as social media,

2. For the most influential theoretical account of the theory of hauntology as the spectral trace that literally haunts by deconstructing the space of ontology, see: Jacques Derrida, Spectres de Marx, Paris, Galilée, 1993. My conception of hauntology differs from Derrida's in theorizing the hauntological as increasingly drawn into presence by the laws of the media. For example, while Marshall McLuhan argued in Understanding Media that technological innovations always play out the fourfold logic of the tetrad (creating, obsolescing, retrieving, and reversing), I would argue this also implies that the tetrad has its dark side, namely that every technological innovation is haunted by that which it extinguishes, substitutes for, inertially maintains in place, and accidents. See particularly: Marshall McLuhan, Understanding Media: The Extensions of Man, Cambridge (Mass.), MIT Press, 2001. 
in order to make of the language of the uncanny, the liminal, the phantasmatic, the hauntological a new way of thinking the future of the archive? After all, thinking the future of the archive immediately involves larger questions ranging from archivalism as a cultural talisman of the fate of the human condition to the psycho-ontological question concerning whether human beings are actually prepared for an archival future enabled by social media, in which nothing is ever really forgotten.

So then, three methodological propositions: the first, ontological, concerns the digital imaginary; the second, epistemological, deals with archives in the wires; and the third, axiological, addresses complexity and the digital archive. In the way of all reversals common to the curved space of digital culture, the fourth proposition-the aesthetic - has already been introduced as a way of reconsidering the future of the archive in the age of social media.

\section{THE DIGITAL IMAGINARY}

Nothing is as purely imaginary as the digital archive. Like a brilliant specter emerging from the vast recesses of the cultural universe, the digital archive sweeps through the night skies of the mind, turning time's past into real-time, lighting up spatial horizons with light-space, folding the historical past into the projected future, breaking down fixed boundaries, always following the unpredictable pathways of the awaiting imagination. Never really interested in truth-telling nor particularly loyal to the concept of bunker archeology, the digital archive is that rarest of cultural phenomena: a code matrix tracing an uncertain arc across the human condition, projecting retrieved memories into the present, here confronting the solid matter of reality with imaginary reconstructions of the past, there gathering speed as the code matrix is propelled forward by the gravitational force-fields of the surrounding planets of society, economy, and culture, always becoming something more intense, more vivid, more purely imaginary, in the process.

Not so much the product of human imagination as its fatal destiny, the digital archive is always shadowed by traces of aesthetic incommensurability. Never really knowable in advance, definitely more than the data contents of its storage memory, always breaking out of its settled codes, the digital archive is animated by imagination, brought alive by creative interpretation, and rendered fully enigmatic by its complexity. While generations of cultural theorists have struggled over the division of spoils between the warring languages of sign and signifier, the digital archive begins from another point, the vanishing point of the object of reflection that represents a liquid sign-slide between referents and 
their coordinate predicates. What Roland Barthes once described as a crossing of the syntagm between metaphor and metonymy is the proper starting-point for understanding the digital archive. ${ }^{3}$ Its ruling sign may be the regime of the digital and its referential logic may be purely archival, but the complex chain of relationships alluded to by the meaning of the term, digital archive, is neither digital nor archival, but precisely the phantasmatic sign-slide at the disappearing centre of their collision.

When the regime of computation, with its dense networks of fast flows of information, collides with archival intelligibility, with its interior depths of meaning, we are finally present at something beyond both the technological and the archival; namely, the emergence of a radically new form of imagination formed precisely at the conjunction of order and chaos. Strangely enough, in this elemental meeting of the materiality of memory and the virtuality of codes, there is to be discovered a renewal of mythic consciousness. While the most ancient of mythologies testifies to the entanglement of conflicting tendencies towards order and chaos as the foundational matter of the cultural universe, something resembling this antinomic struggle is an essential aspect of the digital archive. Here, the material history of the archive is effectively reskinned by the digital, brought out of the shadows of the past into the illumination of a ubiquitous network of screens, and dislodged from internment in inaccessible storage chambers by mobile technologies. While the archival product is, in the end, neither orderly nor chaotic, it does have about it the traces of something primary to human sensibility, namely the creation of the archive in the digital age as something that Martin Heidegger once described as a "dwelling-space, a bridge between past and future, identity and difference." In this case, the digital archive can so powerfully draw the past into presence because this fateful meeting of technology and remembrance is in itself an ongoing act of intermediation linking temporality and spatiality. Indeed, in its most powerful manifestations, the digital archive bears discernable traces of something once thought long surpassed, namely a

3. For a full description of Barthes's concept of the "crossing of the syntagm" in relationship to the question of power, see: Arthur Kroker "The Disembodied Eye: Ideology and Power in the Age of Nihilism," in Arthur Kroker and David Cook, The Postmodern Scene: Excremental Culture and Hyper-Aesthetics Second Edition, New York, St. Martin's Press, 1987, p 73-113; and Arthur Kroker, "The Despotic Sign: Barthes' Rhetoric of Technology," in Arthur Kroker, The Possessed Individual: Technology and the French Postmodern, New York, St. Martin's Press, 1992, p. 82-103.

4. Martin Heidegger, "Building Dwelling Thinking," in Poetry, Language, Thought, trans. Albert Hofstader, New York, Harper Colophon Books, 1971, p. 145-161. 
mythic return of the psychic energy of vitalism as the essence of the archeology of the archive. ${ }^{5}$ When fast computation processes slow memory, when the transcendent power of the code mingles with the in-depth knowledge of the archive, when historical inscription is forced to move at light-speed, the result is a fantastic cultural implosion or, more specifically, the opening up of a space of ambiguity in the previously bounded spaces of the archive. This may account for the vital energy of the digital archive, the fact that the digital archive is a very particular form of dwelling-place, a very specific habitat of memory, knowledge, and interpretation.

\section{ARCHIVES IN THE WIRES}

While traditional archives may have quite properly valorized qualities of preservation, continuity and completeness, the digital archive has a different trajectory. Never bounded it is always fated to circulate in an unbounded digital universe; never solely about preservation, it is ineluctably linked with complex intermediations; never really complete, its destiny is to be fully, and sometimes perhaps fatally, remixed. One does not have to be a technological determinist to recognize that when code meets archive, the silent ideology of the code will always leave its lasting traces. As with other collisions of code and life-digital music, digital books, digital media, digital banking-the code is always aggressive in asserting the imperatives of form over content. Possessing a unique psychic signature, code is most definitely not a neutral order of communication, but something almost animate in its neurological effects. It is simplistic in its emphasis on the hegemony of temporal ordering and stubborn when confronted by ambiguous human desires. Like matter itself, decaying over time, it is resistant to leakages in the ruling ordinal register, object-oriented, and traversed by a singular fascination with the nested, the network, the distributed, the cloud. Code always possesses its

5. Two competing expressions of vitalism are present in this theory of the digital archive: Henri Bergon's conception of "creative evolution" and Martin Heidegger's vision of art as a "dwelling-space" of incommensurability. While Bergon's vision of creative evolution runs parallel to the powerfully utopian conception of technology present in the thought of Teilhard de Chardin and Marshall McLuhan, it does not account for the deeper crisis of technology foretold by Heidegger, namely that "fully completed nihilism" represents a counter-current in technological culture clashing with its possibilities for creativity. See particularly: Henri Bergson, L'évolution créatrice, [1907], Paris, PUF, coll. «Quadrige», 2007; and Martin Heidegger, The Question Concerning Technology and Other Essays: An Introduction to Metaphysics, New Haven and London, Yale University Press, 1987. 
own strict rules of intelligibility concerning the front-end of exchanges between life and computation-specific protocols concerning computation requirements, memory levels, data entry, IP addresses, orders of formatting, translation, circulation, graphics. It imposes a repertoire of strict digital orders concerning the backend of archived data: how will data be stored, how large the archive, protocols concerning accessibility, payment, privacy. And in between the front-end of archives and the speed of computation, there is always present the systems operations logic of the mid-level, that order of computation that compresses flows of data into galaxies of code, transforms archival knowledge into the streamed communication of web sites, mobile technologies, and augmented media.

Consequently, what is the future of archives in the wires? Under the pressure of technological change, the traditional function of the archive as a record of the past appears to have been undermined. In the real-time and real-space of digital culture, distinctions among past, present and future have themselves been increasingly rendered obsolete. When images increasingly constitute the real, when the code matrix replaces the logic of signification, and the language of genetic reproduction substitutes for cultural production, traditional understandings of the archive are in danger of eclipse. Confronted by the speed of digital communication, the archival imagination sometimes panics. Similar to the crisis of cultural intelligibility of the museum, when it was first challenged by the aesthetics of the moving image and, consequently, by the restless motion of multimedia art, archival logic sometimes opts for a purely temporal solution. It attempts to literally freeze the digital object in an isolated moment of time and space. Here, the digital artifact is stripped of its organic relationship to network culture, its code structure rendered motionless, its images cryogenically preserved, its texts bounded, its boundaries perfectly secured from contamination from an always threatening (digital) external environment. But as in life, so in archives: that which has been excluded by the archival imagination will always make its presence felt; that which has been disavowed will often form the basis of spectral hauntologies; and that which has been prohibited will usually prove to be the real object of archival seduction.

In this case, no matter how powerful the will to archival self-preservation, digital culture will find a way of purloining the archival sanctity of bounded artifacts. One code at a time, one essential connection, one electronic synapse, one boundary exchange after another, all digital archives are destined to experience the new digital disease of link rot. Over time, connections fray, software is rendered obsolete, boundaries weaken, operating systems dissolve into liquid arrays of disconnected data points, collections lose their putative meanings. And 
all this because, like the restless movement of time itself, nothing can really stop the degradation of code over time, just as no form of archival logic can do the mythically impossible, namely, to preserve collections of code that always yearns to return to its natural environment-the digital world of speed, fast connectivity, instant interfaces and slow perception. Once infected by frayed connections, broken synapses, and crashed (code) boundaries, digital collections may continue to appear perfectly seamless as a matter of aesthetic appearance, but their destiny is one of digital senescence-literally to slowly erode from within by the gradual, and always terminal, failure of the dense matrix of code. Faced with the sure and certain reality of digital senescence, no archival potion, no aesthetic preservative, no boundary logic can really prevent the unpreventable, specifically, the drift of code back to the elementary matter of the digital universe. Space trash.

\section{COMPLEXITY AND THE DIGITAL ARCHIVE}

At first glance, the digital galaxy is a curious dwelling-place for the traditional archive. While the imagination of the archivist might well be attracted to the global diffusion of knowledge provided by computer networks, by the remarkable capacity of archived objects once fully digitized to be reprocessed, recombined, respliced, refiltered, and by the brilliant speed of network society, this exchange between memory and code is not without its tragic element. Contrary to the extroprian enthusiasm of proponents of the technological imperative, there is much to be said for the necessary solitude of the traditional archive, for, that is, the implicit demands it places on the powers of human imagination to make something meaningful of records so carefully preserved, protected and maintained. As an object of imagination, the traditional archive has its own imperative injunctions, but this order of time has nothing to do with technologies of speed, circulation or diffusion, but only with the core archival event. In solitude, and often on the basis of the accidental encounter of an inquiring mind and a forgotten letter, fragment of a text, recorded interview, moving image, or photograph, that which the philosopher Hannah Arendt once described as the "life of the mind" renews itself. ${ }^{6}$ Something of this sort has always provided the basis for the cultural importance placed by society on its archival knowledge. No matter how neglected, in private conversations and public policy, no matter how little

6. For Arendt, the crucial dilemma confronted by thought in technocractic culture was the emergence of "not-being" as the primary nihilistic impulse immanent to the question of technology itself. See specifically: Hannah Arendt, The Life of the Mind, New York, Harper, Brace, Jovanovic, 1978, p. 50. 
honored in larger debates concerning the immediate priorities of society, the traditional archive has always served as a persistent point of ground truthing of culture and society.

In this case, the power of the archive is that of intermediation: casting the light of the past on the present, foregrounding neglected objects of contemplation, drawing into presence artifacts from the glare of the future. Bridging past and future, reconciling the necessary solitude of the inquiring mind and the complexity of cultural artifacts, the traditional archive does not so much resemble Heidegger's concept of the "dwelling-place," but actually creates anew the "dwelling-place" as a beautifully mediated space of critical and creative cultural reflection. Indeed, what is always at stake in the archival imagination is not simply a question of time, but of space; specifically, the aesthetic challenge inherent in the archival imagination of delicately bringing into presence the different shades of interpretation, those incommensurable spaces of bright clarity, ambiguous gray zones, and dark spaces in the very interpretive complexity of which the story of culture is continuously renewed.

While it would be premature to effect philosophical closure around the dimensions of that form of imagination generated by the digital archive, this much is certain: the digital archive must, as a matter of its deepest ontological requirements, give rise to a form of imagination that is as inflected as it is relational, as recombinant as it is aesthetically indeterminate. Indeed, digital inflections are the essence of archives in the wires. Breaking with traditional visions of the archive as somehow distanced from the complexity of the human condition, the digital archive only exists to the extent that it migrates across the most vital intersections of life: archives of disavowed histories, excluded facts, neglected memories, disowned artifacts, from the purely technological to the resolutely social. The fact that it is a digital archive-simultaneously constituted by and framed in its operating logic, by software codes-implies also that archives in the wire are shaped most profoundly by the logic of the code. If the regime of computation will be relational, recombinant, indeterminate and complex, this means that archives in the wires will also witness an emergent logic of relational data, recombinant memory, indeterminate remixes, and complex figurations. Indeed, if there can be considerable interest among visionary data archivists toward the concept of the "self-generating archive, this is due, in no small part, to the growing realization that wired archives are necessarily reflexive. Like data itself, the digital archive not only assembles complex arrays of data sets, but also exists only in relationship to surrounding data systems. Literally, archives in the wires will be self-generating because it is an essential ontological requirement of code itself that the code 
matrix should exist in dynamic homeostatic exchange with other systems of code; not only recording and responding to on-line queries and new links, but effectively adapting its future behavior to that which is trending in the Net.

The cultural history of the digital archive is not so very different from the history of individual subjects caught up in the future of technoculture. In the $21^{\text {st }}$ century, we both inhabit and are, in turn, inhabited by the electronic world as our primal identity. While we may sometimes wish to disconnect from technology, the world of digital communication definitely appears to be unwilling to disconnect from us. In linking our fate to the story of technology, we may have, quite unintentionally, overlooked the fact that technology has already put its electronic hooks into us. Smart phones provide instantaneous networking for increasingly nomadic bodies. Texting means that we can always be online, both in work and life, in the world of digital communication. The dazzling visual impact of special-effects cinema silently upgrades the speed of human perception to the speed of light. Computer games speed our reflexes and reconfigure our brains. The remix music of hip-hop, electronic samplers, and freestyle composers are how the sounds of technology circulate within the deepest recesses of our imaginations and desires. The ambivalent legacy of biogenetic food and biopharmacology releases the biotech future directly into our bodies. More pervasively than we may suspect, the borders between self and technology have been torn apart. ${ }^{7}$

That we live in a culture of proliferating screens-cinema, television, computers, Androids, iPhones, ABMs, medical imaging, airport surveillance screens-is already a truism: technology as cliché. What is less evident is the silent, but very real, impact of screen culture on our psycho-geography: the psychological territory of human imagination and perception, our sense of space and time, conceptions of what is real and unreal, questions of identity and truthtelling, indeed 'truth-seeing.' In ways complex, often misunderstood and deeply mysterious, we may already be the invisible environment of screens in the wires, exhausted media travelers into whose bodies and minds the psychic surgery of digital technologies of communication puts down its hooks: radically altering the deepest language of human perception, shape-shifting the boundaries of the real, speeding up the meaning of time itself, and transforming visual space into an artificial horizon. Living in a culture dominated by screens in the wires intimates

7. For a fuller description of the cultural imperatives of the technological condition, see Arthur and Marilouise Kroker (eds.), Life in the Wires: The CTheory Reader, Victoria, New World Perspectives, 2004; and Arthur and Marilouise Kroker (eds.), Critical Digital Studies: A Reader, Toronto and Buffalo, University of Toronto Press, 2008. 
that, without our consent and certainly in the absence of conscious deliberation, we have committed ourselves to life as a consciously artificially altered reality.

This implies that studying the larger social context of archives in the wires involves debates about what happens to human subjectivity-questions of consciousness, perception, imagination, representation-when, under the impact of digital communication, human identity is seemingly shattered and fragmented. It also implies that the question of technology is no longer limited to the strict realm of the technological, but permeates culture and society as a whole. Ironically, digital subjects may now have become the archives in the wires that they thought we were only studying from a safe distance. Of course, visionary thinkers like Marshall McLuhan and Teilhard de Chardin sparked a utopian, almost messianic, vision of the digital future, predicting that technology would light up human consciousness, writing the silent memories of oral culture across the sky of the electronic media. However, in the relatively few years after the deaths of these pioneering futurists of digital reality, their dream of a new universal community of understanding has been challenged by the appropriation of digital technology for the brand culture of an increasingly homogenous global capitalist marketplace. Today, globalization in the form of networked capitalism is the dominant economic context for digital culture just as much as Teilhard de Chardin's evocative vision of an electronic "noosphere" has been reduced to the nullity of streamed communication. ${ }^{8}$

Consequently, what is the future of archives in the wires: technotopia or technodystopia? Wired archives as creative materializations of newly emergent visions of digital humanism? Or archives in the wires existing in uneasy tension with the immensely powerful privatizing tendencies of digital capitalism? Or something differing entirely from either of these above-outlined destinies? In this case, it would appear that the central tension of the digital archive occurs precisely at the fold between technotopia and technodystopia. If the wired archive were to fully satisfy the value of conservation, and thus to preserve itself against the circulating logic of the code, the digital archive would essentially have to divest itself of those qualities most dynamic about network culture-intermediation, remix, sampling. Archival preservation is only really possible on the basis of rigorously upholding the aesthetic values of analog culture-bounded frameworks, secured borders, protected data-over the wildness of digital life. On the

8. For an evocative description of the noosphere as the essence of the theory of "creative evolution," see particularly: Teilhard de Chardin, Le phénomène humain [1955], Paris, Éditions du Seuil, coll. «Points», 2007. 
other hand, for the digital archive to be truly wired, for archival imagination to be both for and in the wires, it must break with the value of preservation in favor of digital reflexivity. In this case, the digital archive would be like an object tumbling through the vastness of digital space, intersecting different biographies, challenging imaginations, remixing all the great referentials-a self-generating archive with the added quality of seeking to preserve that which is most incommensurable, most disavowed in received histories of class, ideology, ethnicity, gender, memory, consciousness, race. Never reducible to pure preservation or critical reflexivity, the digital archive would be a creative synthesis of both, a way of preserving cultural absences and relating the contemporary imagination to the always missing archives of the accidental, the disavowed, the incommensurable, the unacknowledged. In this case, the future of the digital archive would rise beyond its current status as a necessarily selective chronicle of the human condition to become that which the archival imagination has always dreamed about, namely a way of drawing into active presence the often forgotten memories of those individuals, cultures, social practices and life histories disappeared by the always specious present of the technological dynamo. So then, the enduring question: how to archive the incommensurable, code the specter, avow the disavowed, honor the silenced and imagine the unimaginable?

For a certainty, technological society has relentlessly moved in the direction of the over-coded, the over-normalized, the over-secured. Everywhere, the will to technology has transformed the philosophical doctrine of nominalism into an epistemological closure, namely, the gathering into the language of code of seemingly everything. What cannot be coded falls outside of cultural legibility. What cannot be normalized is excluded. What cannot be secured is reduced to the realm of the forbidden. Yet for all this, the fatal cycle of reversal present in all things will have its final say. This means that the triumph of the code probably indicates that a fatal precession of the language of code is already in motion, that a fundamental principle of repolarization is under way. In this case, the future of the archive, in a society where increasingly everything must be coded, would be in the way of drawing into presence precisely that which resists the code, that which, in effect, represents that most indiscernible of all fractures which, now as always, constitutes the fateful beginning of a form of cultural imagination that repolarizes the death of code with the life of imagination. 